\title{
Prediction of autonomic dysreflexia during urodynamics: a prospective cohort study
}

\author{
Matthias Walter ${ }^{1,3 \dagger}$ (D), Stephanie C. Knüpfer ${ }^{1 \dagger}$, Jacquelyn J. Cragg ${ }^{2,3}$, Lorenz Leitner ${ }^{1}$, Marc P. Schneider ${ }^{1}$, \\ Ulrich Mehnert ${ }^{1}$, Andrei V. Krassioukov ${ }^{3}$, Martin Schubert ${ }^{2}$, Armin Curt ${ }^{2}$ and Thomas M. Kessler ${ }^{1 *}$
}

\begin{abstract}
Background: Autonomic dysreflexia is a severe and potentially life-threatening condition in patients with spinal cord injury, as it can lead to myocardial ischemia, brain hemorrhage, or even death. Urodynamic investigation is the gold standard to assess neurogenic lower urinary tract dysfunction due to spinal cord injury and reveal crucial pathological findings, such as neurogenic detrusor overactivity. However, neurogenic detrusor overactivity and urodynamic investigation are known to be leading triggers of autonomic dysreflexia. Therefore, we aimed to determine predictors of autonomic dysreflexia in individuals with spinal cord injury during urodynamic investigation.
\end{abstract}

Methods: This prospective cohort study included 300 patients with spinal cord injuries and complete datasets of continuous non-invasive cardiovascular monitoring, recorded during same session repeat urodynamic investigation. We used logistic regression to reveal predictors of autonomic dysreflexia during urodynamic investigation.

Results: We found that level of injury and presence of neurogenic detrusor overactivity were the only two independent significant predictors for autonomic dysreflexia during urodynamic investigation. A lesion at spinal segment T6 or above (odds ratio (OR) 5.5, 95\% Cl 3.2-9.4) compared to one at T7 or below, and presence of neurogenic detrusor overactivity (OR 2.7, 95\% confidence interval (CI) 1.4-4.9) were associated with a significant increased odds of autonomic dysreflexia during urodynamic investigation. Both odds persisted after adjustment for age, sex, and completeness and stage of injury (adjusted OR (AOR) 6.6, 95\% Cl 3.8-11.7, and AOR 2.2, 95\% Cl 1.1-4.5, respectively). Further stratification by lesion level showed leveldependent significantly increased adjusted odds of autonomic dysreflexia, i.e., from C1-C4 (AOR 16.2, 95\% Cl 5.9-57.9) to T4-T6 (AOR 2.6, 95\% Cl 1.3-5.2), compared to lesions at T7 or below.

Conclusions: In patients with neurogenic lower urinary tract dysfunction due to spinal cord injury, autonomic dysreflexia is independently predicted by lesion level and presence of neurogenic detrusor overactivity.

Considering the health risks associated with autonomic dysreflexia, such as seizures, stroke, retinal bleeding, or even death, we recommend both continuous cardiovascular monitoring during urodynamic investigation in all spinal cord-injured patients with emphasis on those with cervical lesions, and appropriate neurogenic detrusor overactivity treatment to reduce the probability of potentially life-threatening complications.

Trial registration: ClinicalTrials.gov, NCT01293110.

Keywords: Autonomic dysreflexia, Neurogenic detrusor overactivity, Neurogenic lower urinary tract dysfunction, Prediction, Spinal cord injury, Urodynamic investigation

\footnotetext{
* Correspondence: tkessler@gmx.ch

${ }^{\dagger}$ Equal contributors

${ }^{1}$ Neuro-Urology, Spinal Cord Injury Center \& Research, University of Zürich,

Balgrist University Hospital, Zürich, Switzerland

Full list of author information is available at the end of the article
} 


\section{Background}

Spinal cord injury (SCI), a devastating event [1], is acquired by almost half a million people each year worldwide [2]. Besides motor recovery, i.e., the ability to walk or utilize the upper extremities, lower urinary tract (LUT) [3, 4] and cardiovascular system (CVS) [5] function are among the primary priorities for patients with SCI [6]. Autonomic dysreflexia (AD) [7], a severe, potentially lifethreatening condition affecting the CVS following SCI that can occur more than 40 times a day [8], is elicited by either noxious (e.g., pain) and innocuous stimuli (e.g., bladder filling) from below the level of injury [9]. If misdiagnosed or poorly managed, AD can result in disastrous consequences [10], including myocardial ischemia [11], brain hemorrhage [12], seizures [13], and even death [14].

Urodynamic investigation (UDI) is the gold standard to assess neurogenic lower urinary tract dysfunction (NLUTD) in patients with SCI [3, 4], but it may induce AD $[15,16]$. Considering that it is currently not possible to know in advance which patient will experience $A D$ during UDI and, of those with $\mathrm{AD}$, to what extent the systolic blood pressure (SBP) will increase, we aimed to determine the overall incidence and predictors of $\mathrm{AD}$ during UDI.

\section{Methods}

\section{Participants and study design}

This prospective cohort study was conducted at a single university SCI center between January 2011 and December 2016. Inclusion criteria were patients with NLUTD due to suprasacral SCI and age of at least 18 years. Exclusion criteria were symptomatic urinary tract infections (i.e., positive urine culture and clinical symptoms including fever), pressure ulcers at the time of UDI, and incomplete data of cardiovascular monitoring (CVM) during UDI. Overall, 300 patients (41 females and 259 males, mean age $51 \pm 16$ years, mean duration since SCI $10 \pm 12$ years) with complete cardiovascular recordings were included for analysis. The patients' characteristics are shown in Table 1. This study was approved by the local ethics committee and is registered at ClinicalTrials.gov (NCT01293110). All patients gave written informed consent according to the Helsinki II declaration.

\section{Predictor variables and outcomes}

The neurological level and completeness of SCI, i.e., sensorimotor impairment, were determined using the American Spinal Injury Association Impairment Scale (AIS) according to the International Standards for Neurological Classification of Spinal Cord Injury (ISNCSCI) [17]. The stage of injury was classified as acute (less than 300 days since injury) and chronic (more than 300 days since injury), in accordance with the European Multicenter Study about Spinal Cord Injury (EMSCI, www.emsci.org) definition.
All methods, definitions, and units are in line with the standards recommended by the International Continence Society (ICS) [18, 19]. All patients were asked to empty their bladder and bowels prior to the UDI, which was performed according to Good Urodynamic Practice following the recommendations of the ICS [18].

Individuals were investigated in a sitting position, whenever possible, which reflects the position of an individual with SCI when emptying the bladder, e.g., using intermittent self-catheterization, while sitting in a wheelchair or on a toilet. A 7 French transurethral latex-free single-use catheter and a common rectal catheter for simultaneous measurements of vesical and abdominal pressure were used. Since rectal manipulation itself can elicit AD [20], UDI was only initiated in the absence of $\mathrm{AD}$. The bladder was filled retrograde with a $37^{\circ} \mathrm{C}$ mixture of $0.9 \%$ sodium chloride solution and contrast medium.

All patients underwent same session repeat UDI [21], i.e., two consecutive measurements, using a multichannel urodynamic system (Sedia ${ }^{\circ}$, Givisiez, Switzerland). Continuous cardiovascular monitoring (Finometer ${ }^{\circledR} \mathrm{PRO}$, Finapres Medical Systems (FMS), Amsterdam, The Netherlands) [22] was applied to enable a non-stop "beat-to-beat" documentation of SBP, diastolic BP (DBP), and heart rate (HR) synchronous to the ongoing UDI. $\mathrm{AD}$ (the primary outcome) was defined according to the International Standards to document remaining Autonomic Function after SCI (ISAFSCI) as an increase in $\mathrm{SBP} \geq 20 \mathrm{mmHg}$ from baseline [23]. In case of clinical signs of $\mathrm{AD}$ such as headache, flushing, sweating, and piloerection [24, 25], UDI was stopped immediately and the bladder was emptied.

\section{Statistical analysis}

Continuous variables including age, time since injury, SBP, DBP, and HR were visually inspected for normal distribution by using Q-Q plots. Normally distributed data were analyzed using analysis of variance (ANOVA) or unpaired $t$ tests to compare between groups. Results are presented as mean \pm standard deviation (SD) or $95 \%$ confidence intervals (CIs), respectively. The $k$ statistic was used to investigate agreement of the presence or absence of AD between the two UDI sessions. A chisquare test or Fisher's exact test were used to assess the relationship between categorical variables.

Logistic regression (bivariable and multivariable) was used to investigate predictors of AD during UDI. Unadjusted odds ratios (ORs) and adjusted odds ratios (AORs) are presented with corresponding 95\% CI. Statistical significance was defined as a $p$ value of less than 0.05. Statistical analyses were performed using R Studio version 1.0.136 (Integrated Development for R, RStudio, Inc., Boston, MA, USA). 
Table 1 Patients' characteristics and cardiovascular changes

\begin{tabular}{|c|c|c|c|c|}
\hline Characteristics & All patients $(n=300)$ & Female $(n=41)$ & Male $(n=259)$ & $p$ value \\
\hline Mean (SD) age (years) & $51(16)$ & $57(18)$ & $51(16)$ & 0.016 \\
\hline Mean (SD) time after SCl (years) & $10(12)$ & $6(10)$ & $11(12)$ & 0.019 \\
\hline \multicolumn{5}{|l|}{ Stage of $\mathrm{SCl}^{\mathrm{a}}$} \\
\hline Acute vs. chronic, no. (\%) & 68 (23) vs. 232 (7) & 16 (39) vs. 25 (61) & 52 (20) vs. 207 (80) & 0.007 \\
\hline \multicolumn{5}{|l|}{ Type of plegia } \\
\hline Tetraplegic vs. paraplegic, no. (\%) & 98 (33) vs. 202 (67) & 11 (27) vs. 30 (73) & 87 (45) vs. $172(65)$ & 0.391 \\
\hline \multicolumn{5}{|l|}{ Completeness of lesion (AIS) } \\
\hline Complete (AIS A) vs. incomplete (AIS B-D), no. (\%) & $120(40)$ vs. $180(60)$ & 9 (22) vs. 32 (78) & 111 (43) vs. 148 (57) & 0.011 \\
\hline $\begin{array}{l}\text { Motor complete (AIS A-B) vs. incomplete } \\
\text { (AIS C-D), no. (\%) }\end{array}$ & 170 (57) vs. $130(43)$ & 15 (37) vs. 26 (63) & 155 (60) vs. $104(40)$ & 0.005 \\
\hline AIS A, no. (\%) & $120(40)$ & $9(22)$ & $111(43)$ & \\
\hline AIS B, no. (\%) & $50(17)$ & $6(15)$ & $44(17)$ & \\
\hline AIS C, no. (\%) & $45(15)$ & $9(22)$ & $36(14)$ & \\
\hline AIS D, no. (\%) & $85(28)$ & $17(41)$ & $68(26)$ & \\
\hline \multicolumn{5}{|l|}{ Lesion level } \\
\hline At or above T6 vs. below T6, No. (\%) & 166 (55) vs. 134 (45) & 16 (39) vs. 25 (61) & 150 (58) vs. 109 (42) & 0.024 \\
\hline Cervical, no. (\%) & $98(33)$ & $11(27)$ & $87(33)$ & \\
\hline Thoracic, no. (\%) & $172(57)$ & $20(49)$ & $152(59)$ & \\
\hline Lumbar (L1-L2), no. (\%) & $30(10)$ & $10(24)$ & $20(8)$ & \\
\hline \multicolumn{5}{|l|}{ Start of UDI } \\
\hline \multicolumn{5}{|l|}{ Blood pressure } \\
\hline Mean (SD) systolic (mmHg) & $127(23)$ & $123(24)$ & $127(23)$ & 0.237 \\
\hline Mean (SD) diastolic (mmHg) & $76(13)$ & $71(15)$ & $76(13)$ & 0.010 \\
\hline Mean (SD) heart rate (bpm) & $75(15)$ & $76(14)$ & $75(16)$ & 0.956 \\
\hline \multicolumn{5}{|l|}{ Cardiovascular change $(\Delta)$ during $\mathrm{UDI}^{\mathrm{b}}$} \\
\hline \multicolumn{5}{|l|}{ Blood pressure } \\
\hline Mean (SD) systolic (mmHg) & $42(34)$ & $38(22)$ & $43(35)$ & 0.384 \\
\hline Mean (SD) diastolic (mmHg) & $17(14)$ & $18(12)$ & $17(14)$ & 0.697 \\
\hline Mean (SD) heart rate (bpm) & $-8(14)$ & $-5(10)$ & $-8(15)$ & 0.086 \\
\hline \multicolumn{5}{|l|}{ Presence of $\mathrm{NDO}^{\mathrm{b}}$} \\
\hline Yes vs. No, no. (\%) & 249 (83) vs. 51 (17) & 34 (83) vs. 7 (17) & 215 (83) vs. 44 (17) & 0.989 \\
\hline
\end{tabular}

Statistically significant differences $(p<0.05)$ between female and male patients are highlighted in bold

All values are presented as mean (SD) or number of patients (\%)

aSCl defined as "acute" upon 300 days since injury and "chronic" after 300 days according to the European Multicenter Study about Spinal Cord Injury (EMSCl, www.emsci.org)

${ }^{\mathrm{b}}$ Indicating the worse of two same session UDls

AIS American Spinal Injury Association (ASIA) Impairment Scale, NDO neurogenic detrusor overactivity, SCI spinal cord injury, SD standard deviation,

UDI urodynamic investigation

\section{Results}

\section{Overall incidence and repeatability of autonomic} dysreflexia during urodynamic investigation

The overall incidence of AD during UDI was $68 \%$ (204/300). AD was found in 176 (59\%) vs. 162 (54\%) of the 300 patients during the first and the second UDI, respectively. In 66\% (134/204) of patients with $\mathrm{AD}$, an increase in SBP of at least $20 \mathrm{mmHg}$ was elicited during both UDIs. Hence, in more than one third of all patients with AD (70/204), bladder filling elicited
AD in only one of two UDIs. The repeatability of detecting AD between the two same session UDIs was moderate $(k=0.53,95 \% \mathrm{CI}-0.4$ to 1.5$)$. Characteristics of clinical symptoms presented by $37 \%$ (75/204) of patients with AD during UDI are shown in Fig. 1. We did not observe any imminent complication as a result of the increase in SBP associated with AD during UDI. All patients were monitored until SBP returned to baseline values and, whenever present, clinical symptoms disappeared. 


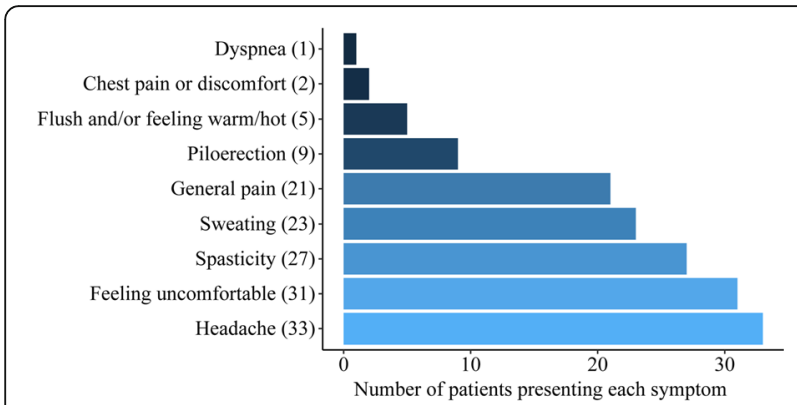

Fig. 1 Characteristics of clinical symptoms related to autonomic dysreflexia (AD) during urodynamic investigation. In 75 patients with symptomatic AD, 152 counts of clinical symptoms were recorded. Headache with 33 counts was the most frequent symptom. The remaining 119 counts included feeling uncomfortable (31), spasticity (27), sweating (23), general pain (21), piloerection (9), flushing and/or feeling warm/hot (5), chest pain or discomfort (2), and dyspnea (1)

\section{Prediction of autonomic dysreflexia during urodynamic investigation}

Logistic regression analyses (Table 2 ) revealed that the lesion level, i.e., T6 or above vs. T7 or below, as well as the presence of neurogenic detrusor overactivity (NDO) predicted AD during UDI. Further stratification by lesion level showed a significantly increasing odds of AD with higher lesion levels. When comparing patients with NDO and without NDO, statistically significant increases in SBP and DBP were observed, while changes in HR did not significantly differ between both groups (Fig. 2).

\section{Differences between patients with and without autonomic dysreflexia}

When comparing patients with $\mathrm{AD}$ and without $\mathrm{AD}$, statistically significant differences in SBP, DBP, and HR were observed (Table 3). Remarkably, almost one third $(65 / 204,32 \%)$ of the patients with AD had a lesion below T6.

\section{Characteristics of spinal cord injury affect cardiovascular changes in patients with autonomic dysreflexia}

Exploring cardiovascular changes during UDI within the group of patients with $\mathrm{AD}$, we found several significant differences related to SCI severity, i.e., the level and the completeness of the lesion, and the presence of clinical symptoms. Specifically, patients with cervical lesions experienced a significantly higher increase in SBP during UDI compared to those with a thoracic and lumbar lesion (Additional file 1). Patients with lesions at T6 or above showed a significantly higher increase in SBP and a greater decrease in HR compared to those with a lesion at T7 or below (Fig. 3). When stratifying patients with $\mathrm{AD}$ according to the AIS, significantly different changes in HR were discovered between AIS A and AIS C, AIS A and AIS D, and AIS B and AIS D (Additional file 1). Patients suffering from a complete lesion (AIS A) compared to those with an incomplete lesion (AIS BD) showed a significantly greater decrease in $\mathrm{HR}$ (Additional file 1). Patients with a motor complete lesion (AIS A-B) compared to those with a motor incomplete lesion (AIS C-D) had a significantly higher increase in SBP and a greater decrease in HR (Additional file 1). Patients with symptomatic compared to asymptomatic AD demonstrated a significantly higher increase in SBP and DBP as well as a greater decrease in HR (Fig. 4). No significant cardiovascular changes were found for $\mathrm{AD}$ patients with acute compared to those with chronic suprasacral SCI (Additional file 1).

\section{Discussion}

In this prospective cohort study including 300 patients, we found a high incidence of AD in about two thirds of our patients with NLUTD due to suprasacral SCI. In addition, we identified the level of SCI as well as the presence of NDO as independent significant predictors to experience AD during UDI. Importantly, almost one third of our patients with AD had a lesion level below T6.

A high number of physicians and other healthcare professionals may not be aware of $\mathrm{AD}$, unless their patient population includes individuals with SCI [26]. Thus, the lack of experience with AD-related SBP changes might lead to misdiagnosed AD and even acceptance of the potential risk of life-threatening complications during UDI. Providing evidence on what constitutes an increased risk for experiencing $\mathrm{AD}$ during UDI, i.e., predictors, could lead to a safer way to perform UDI in this cohort. Most importantly, education regarding $\mathrm{AD}$, i.e., knowledge transfer to physicians, other health professionals, caregivers, and especially patients and family members is crucial to raise awareness of $\mathrm{AD}$ so that $\mathrm{AD}$-related complications during UDI and in everyday life (including emergency room admissions for "not feeling right" or urinary tract symptoms) can be minimized or prevented at best.

In contrast to episodic BP measurement, which has often been used to record AD during UDI [27-29], continuous CVM provides a more accurate observation, as it allows one to detect short episodes of AD. The "beatto-beat" technique allows the Finometer (via finger photoplethysmography) to monitor cardiovascular changes of SBP, DBP, and HR continuously and accurately according to the Association for the Advancement of Medical Instrumentation. Furthermore, the British Hypertension Society has recommended the Finometer for measurements in the clinical set-up and for research purposes. In line with Liu et al. [9] and our previous study [16], we used continuous CVM to document SBP, DBP, and HR, i.e., "beat-to-beat" recordings, throughout 
Table 2 Odds ratios for autonomic dysreflexia during urodynamics

\begin{tabular}{|c|c|c|c|c|}
\hline Variable & Unadjusted OR (95\% Cl) & $p$ value & Adjusted OR (95\% Cl) & $p$ value \\
\hline \multicolumn{5}{|l|}{ Sex } \\
\hline Male $^{a}$ & 1 & & 1 & \\
\hline Female & $2.1(1.0-5.1)$ & 0.070 & $2.0(0.9-4.9)$ & 0.101 \\
\hline \multicolumn{5}{|l|}{ Stage of $\mathrm{SCl}^{\mathrm{b}}$} \\
\hline Acute & $1.2(0.7-2.1)$ & 0.600 & $0.8(0.4-1.7)$ & 0.622 \\
\hline Chronic $^{\mathrm{a}}$ & 1 & & 1 & \\
\hline \multicolumn{5}{|l|}{ AIS } \\
\hline A & $0.9(0.5-1.6)$ & 0.719 & $1.4(0.7-2.9)$ & 0.700 \\
\hline B & $1.2(0.6-2.6)$ & 0.646 & $1.7(0.7-4.3)$ & 0.360 \\
\hline C & $1.0(0.5-2.3)$ & 0.939 & $1.2(0.5-2.9)$ & 0.850 \\
\hline$D^{a}$ & 1 & & 1 & \\
\hline \multicolumn{5}{|c|}{ Complete vs. incomplete SCI } \\
\hline AIS A-B & $0.9(0.5-1.4)$ & 0.510 & $1.1(0.7-2.0)$ & 0.657 \\
\hline AIS C-D & 1 & & 1 & \\
\hline \multicolumn{5}{|c|}{ Motor complete vs. incomplete SCI } \\
\hline AIS A & $1.0(0.6-1.6)$ & 0.880 & $1.4(0.8-2.6)$ & 0.250 \\
\hline AIS B-D ${ }^{a}$ & 1 & & 1 & \\
\hline \multicolumn{5}{|c|}{ Lesion level, cutoff at T6 } \\
\hline At or above T6 & $5.5(3.2-9.4)$ & $<0.001$ & $6.6(3.8-11.7)$ & $<0.001$ \\
\hline T7 and below ${ }^{\mathrm{a}}$ & 1 & & 1 & \\
\hline \multicolumn{5}{|c|}{ Lesion level, distributions above T7 } \\
\hline $\mathrm{C} 1-\mathrm{C} 4$ & $13.9(5.2-48.8)$ & $<0.001$ & $16.2(5.9-57.9)$ & $<0.001$ \\
\hline $\mathrm{C} 5-\mathrm{C} 8$ & $8.5(3.5-23.8)$ & $<0.001$ & $12.2(4.9-35.8)$ & $<0.001$ \\
\hline $\mathrm{T} 1-\mathrm{T} 3$ & $4.3(1.8-11.7)$ & 0.002 & $5.2(2.1-14.5)$ & 0.001 \\
\hline T4-T6 & $2.4(1.3-4.7)$ & 0.007 & $2.6(1.3-5.2)$ & 0.006 \\
\hline T7 and below ${ }^{a}$ & 1 & & 1 & \\
\hline \multicolumn{5}{|c|}{ Presence of NDO during $\mathrm{UDI}^{\mathrm{C}}$} \\
\hline Yes & $2.7(1.4-4.9)$ & 0.002 & $2.2(1.1-4.5)$ & 0.030 \\
\hline $\mathrm{No}^{\mathrm{a}}$ & 1 & & 1 & \\
\hline
\end{tabular}

Statistically significant differences $(p<0.05)$ for the categorical variables against its own reference category are highlighted in bold

All values are presented as OR $(95 \% \mathrm{Cl})$

Bivariate logistic regression analysis between $A D$ and each categorical variable resulted in crude OR. Multivariate logistic regression analysis between $A D$ and all

categorical variables including age (as a continuous variable) in one model resulted in adjusted OR

${ }^{a}$ Reference category

b $\mathrm{SCl}$ defined as "acute" upon 300 days since injury and "chronic" after 300 days according to the European Multicenter Study about Spinal Cord Injury (EMSCl, www.emsci.org)

Indicating the worse of two same session UDIs

$A D$ autonomic dysreflexia, AIS American Spinal Injury Association (ASIA) Impairment Scale, C cervical, $C$ confidence interval, NDO neurogenic detrusor overactivity, $O R$ odds ratio, $S C l$ spinal cord injury, $T$ thoracic, UDI urodynamic investigation

the entire investigation to immediately reveal $\mathrm{AD}$. In fact, AD was detected during UDI in more than two thirds $(204 / 300)$ of our patients. In contrast, previous literature measuring BP episodically reported incidence of AD between 37 and $43 \%$. This lower incidence of $A D$ might be attributed to intermittent instead of continuous CVM, as the former is likely to miss short-term episodes of $\mathrm{AD}$ [27-29]. Evidence for this hypothesis is given, as we recently found a similarly high incidence of $\mathrm{AD}$ (73\%) in women with NLUTD due to suprasacral SCI
[16]. Thus, AD during UDI in individuals with SCI seems to be generally underestimated, and this might put our patients at relevant risk if $\mathrm{AD}$ is not detected and appropriately managed.

Sympathetic pre-ganglionic neurons (SPNs) are regarded as the pivotal spinal neurons for central cardiovascular control [30]. It is commonly believed that $\mathrm{AD}$ occurs in patients with SCI at or above T6 [31, 32], and most studies have only presented data in this selected cohort [9, 27, 29, 33]. However, $\mathrm{AD}$ can also occur in patients with a lesion level 

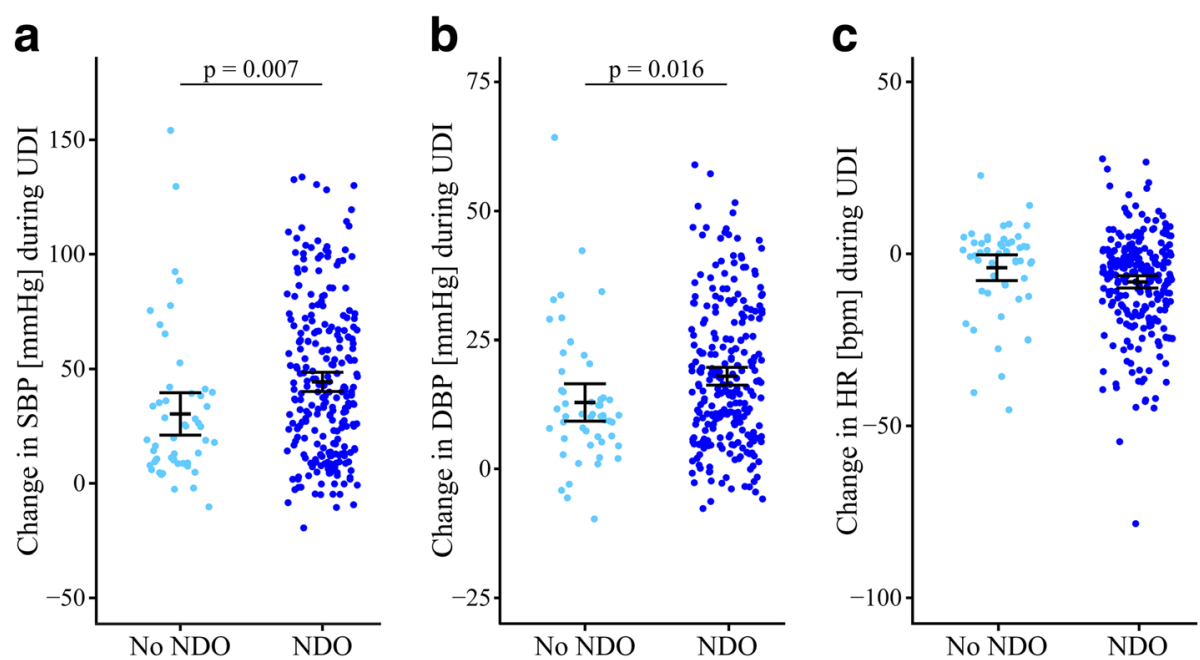

Fig. 2 Cardiovascular parameters during urodynamic investigation by presence of neurogenic detrusor overactivity. Cardiovascular changes in (a) SBP, (b) DBP, and (c) HR in SCl patients who have either presented NDO (right side in dark blue) or not (left side in Maya blue). At the start of UDI, cardiovascular parameters were not significantly different between both groups. In patients with NDO, cardiovascular changes in SBP (44, 95\% Cl 40.2-48.6 vs. 30, 95\% Cl 21.1-39.6 mmHg, $p=0.007)$ and DBP (18,95\% Cl 16.3-19.8 vs. 13, 95\% Cl 9.3-16.6 mmHg, $p=0.016)$ during UDI were significantly different compared to patients without NDO. Changes in $\mathrm{HR}(-8,95 \% \mathrm{Cl}-10.0$ to $-6.4 \mathrm{vs} .-4,95 \% \mathrm{Cl}-7.7$ to -0.4$)$ did not significantly $(p=0.06)$ differ between both groups. Each circle represents one patient's cardiovascular changes during UDI. Error bars represent mean and the $95 \% \mathrm{Cl}$ of cardiovascular changes; i.e., the worse out of two same session UDls was used. BPM beats per minute, Cl confidence interval, DBP diastolic blood pressure, HR heart rate, NDO neurogenic detrusor overactivity, SBP systolic blood pressure, SCI spinal cord injury, UDI urodynamic investigation

below T6, as the sympathetic outflow originates from T1 to L2 [34] and supplies various regions, such as the heart (T1T5) and urinary bladder (L1-L2) [35]. Thus, similar to Huang et al. [28], we also included patients with SCI below $\mathrm{T} 6$, and about one third of patients with $\mathrm{AD}$ in our study had a lesion below T6. The sympathetic postganglionic neurons, excited by SPNs, synapse with target organs, such as the heart and blood vessels, and hence are responsible for the innervation of the splanchnic vascular bed [32]. The higher the level of injury, the more SPNs are likely to be independent of central inhibition. Therefore, a growing number of independent SPNs receiving afferent input from below the level of injury could provide the critical mass of vasoconstriction needed to elevate the SBP accordingly [31]. To provide further evidence on the impact of lesion level on cardiovascular changes, increase in SBP from baseline in patients experiencing $\mathrm{AD}$ during UDI was highest in those with a cervical injury, followed by those with a thoracic and lumbar injury, respectively. In patients with a lesion below T6, it is thought that either sympathetic innervation of vascular structures remains sufficiently under supraspinal sympathetic control [36], or the extent of disconnected vascular areas is reduced, leading to a normal inhibitory response to baroreceptor-mediated reflexes to maintain homeostasis.

$\mathrm{AD}$ can also be asymptomatic, known as silent $\mathrm{AD}$ [29, 33]. Remarkably, 63\% (129/204) of our patients with $\mathrm{AD}$ were asymptomatic. This condition can be very hazardous, because the discrepancy between cardiovascular changes and clinical symptoms might be misunderstood by physicians and therefore assigned incorrectly to other causes, which could lead to life-threatening situations. The group of 75 patients with symptomatic AD (37\%) had significantly greater changes in all three cardiovascular domains, i.e., SPB, DBP, and HR, and consisted of more patients with a lesion level at or above T6 and complete lesions (AIS A) compared to those with asymptomatic AD.

Considering the distribution of the lesion level, i.e., at or above T6 vs. below T6, more patients who were asymptomatic had a lesion below T6. While preserved central control of SPNs allows inhibitory descending signals to counterattack the vasoconstriction, individuals with a lesion above T6 are lacking central control of SPNs that innervate the heart (T1-T5). The higher the lesion above T6, the more likely a patient will show a slowing down of the heartbeat, potentially result in bradycardia. This reflects the parasympathetic effort to respond to the sudden SBP increase in reducing the heart stroke volume through the vagal nerve. This may ultimately result in a deterioration of the patient's condition.

In line with the literature [37], our AD patients with an AIS A lesion demonstrated a significantly greater decrease in HR than those with an AIS B-D lesion, indicating that the greater the extent of the injury, i.e., the fewer efferent fibers are spared to uphold central 
Table 3 Baseline characteristics and cardiovascular changes: differences between patients with and without AD

\begin{tabular}{|c|c|c|c|}
\hline Characteristics & No $\mathrm{AD}(n=96)$ & $\mathrm{AD}(n=204)$ & $p$ value \\
\hline \multicolumn{4}{|l|}{ Sex } \\
\hline Male vs. female, no. (\%) & 88 (92) vs. 8 (8) & 171 (84) vs. 33 (16) & 0.065 \\
\hline Mean (SD) age (years) & $49(15)$ & $53(16)$ & 0.044 \\
\hline Mean (SD) time after SCl (years) & $10(10)$ & $11(12)$ & 0.706 \\
\hline \multicolumn{4}{|l|}{ Stage of $\mathrm{SCl}^{\mathrm{a}}$} \\
\hline Acute vs. chronic, no. (\%) & 20 (21) vs. 76 (79) & 48 (23) vs. 156 (77) & 0.603 \\
\hline \multicolumn{4}{|l|}{ Type of plegia } \\
\hline Tetraplegic vs. paraplegic, no. (\%) & $10(10)$ vs. $86(90)$ & 88 (43) vs. $116(57)$ & $<0.001$ \\
\hline \multicolumn{4}{|l|}{ Completeness of lesion (AIS) } \\
\hline Complete (AIS A) vs. incomplete (AIS B-D), no. (\%) & 41 (43) vs. 55 (57) & 79 (39) vs. 125 (61) & 0.511 \\
\hline $\begin{array}{l}\text { Motor complete (AIS A-B) vs. incomplete } \\
\text { (AIS C-D), no. (\%) }\end{array}$ & 55 (57) vs. 41 (43) & 115 (56) vs. 89 (44) & 0.881 \\
\hline AIS A, no. (\%) & $41(43)$ & $79(39)$ & \\
\hline AIS B, no. (\%) & $14(15)$ & $36(18)$ & \\
\hline AIS C, no. (\%) & $14(15)$ & $31(15)$ & \\
\hline AIS D, no. (\%) & $27(28)$ & $58(28)$ & \\
\hline \multicolumn{4}{|l|}{ Lesion level } \\
\hline At or above T6 vs. below T6, no. (\%) & 27 (28) vs. 69 (72) & 139 (68) vs. 65 (32) & $<0.001$ \\
\hline Cervical, no. (\%) & $10(10)$ & $88(43)$ & \\
\hline Thoracic, no. (\%) & $72(75)$ & $100(49)$ & \\
\hline Lumbar (L1-L2), no. (\%) & $14(15)$ & $16(8)$ & \\
\hline \multicolumn{4}{|l|}{ Start of UDI ${ }^{b}$} \\
\hline \multicolumn{4}{|l|}{ Blood pressure } \\
\hline Mean (SD) systolic (mmHg) & $133(22)$ & $124(23)$ & 0.001 \\
\hline Mean (SD) diastolic (mmHg) & $79(15)$ & $74(12)$ & 0.001 \\
\hline Mean (SD) heart rate (bpm) & $74(15)$ & $76(16)$ & 0.458 \\
\hline \multicolumn{4}{|l|}{ Cardiovascular change $(\Delta)$ during $\left.U D\right|^{b}$} \\
\hline \multicolumn{4}{|l|}{ Blood pressure } \\
\hline Mean (SD) systolic (mmHg) & $7(8)$ & $58(29)$ & $<0.001$ \\
\hline Mean (SD) diastolic (mmHg) & $5(6)$ & $23(13)$ & $<0.001$ \\
\hline Mean (SD) heart rate (bpm) & $1(8)$ & $-11(15)$ & $<0.001$ \\
\hline \multicolumn{4}{|l|}{ Presence of NDO ${ }^{b}$} \\
\hline Yes vs. No, no. (\%) & 70 (73) vs. 26 (27) & 179 (88) vs. 25 (12) & 0.001 \\
\hline
\end{tabular}

Statistically significant differences $(p<0.05)$ between patients with and without autonomic dysreflexia are highlighted in bold

All values are presented as mean (SD) or number of patients (\%)

${ }^{a} \mathrm{SCl}$ defined as "acute" upon 300 days since injury and "chronic" after 300 days according to the European Multicenter Study about Spinal Cord Injury (EMSCl, www.emsci.org)

${ }^{b}$ Indicating the worse of two same session UDIs

$A D$ autonomic dysreflexia, AIS American Spinal Injury Association (ASIA) Impairment Scale, NDO neurogenic detrusor overactivity, SCI spinal cord injury,

$S D$ standard deviation, UDI urodynamic investigation

sympathetic control of the heart, the greater the influence on HR by the parasympathetic nervous system. In contrast to our observation, Giannantoni et al. [27] reported that $\mathrm{AD}$ did not correlate with the completeness of a lesion. These discrepancies might be attributed to differences in cardiovascular assessment, individual number, and characteristics of SCI, hampering a meaningful comparison but warranting further investigation of these issues. It should be acknowledged that the extent of an SCI reaches beyond the sensorimotor impairment. Whether an SCI is autonomic complete, i.e., supraspinal sympathetic control is entirely lost, or not seems to have a significant influence on blood pressure and heart rate. According to the review by West et al. [38] in patients with chronic SCI, the autonomic completeness of $\mathrm{SCI}$ is more strongly related to 

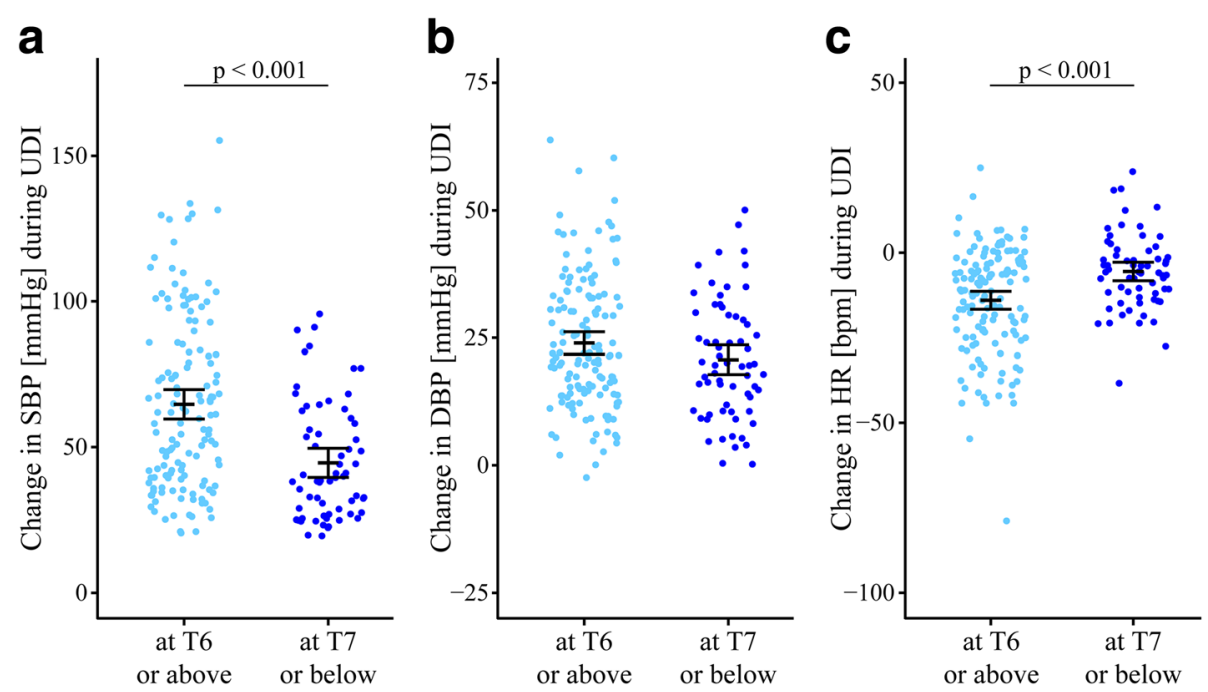

Fig. 3 Cardiovascular changes during urodynamic investigation by lesion level (cutoff T6). Cardiovascular changes in (a) SBP, (b) DBP, and (c) HR in $\mathrm{SCl}$ patients with $\mathrm{AD}$ who have either sustained a SCl at T6 or above (left side in Maya blue) or at T7 or below (right side in dark blue). At the start of UDI, cardiovascular parameters were not significantly different between both groups. In patients with a SCl at T6 or above, cardiovascular changes in SBP $(65,95 \% \mathrm{Cl} 59.7-69.7$ vs. $45,95 \% \mathrm{Cl} 39.6-49.5 \mathrm{mmHg})$ and $\mathrm{HR}(-14,95 \% \mathrm{Cl}-16.6$ to -11.4 vs. $-6,95 \% \mathrm{Cl}-8.2$ to -2.9 bpm) were significantly different $(p<0.001)$ compared to those of remaining patients. Each circle represents one patient's cardiovascular changes during UDI. Error bars represent mean and the $95 \% \mathrm{Cl}$ of cardiovascular changes; i.e., the worse out of two same session UDIs were used. AD autonomic dysreflexia, BPM beats per minute, Cl confidence interval, DBP diastolic blood pressure, HR heart rate, SBP systolic blood pressure, SCI spinal cord injury, $T$ thoracic, UDI urodynamic investigation
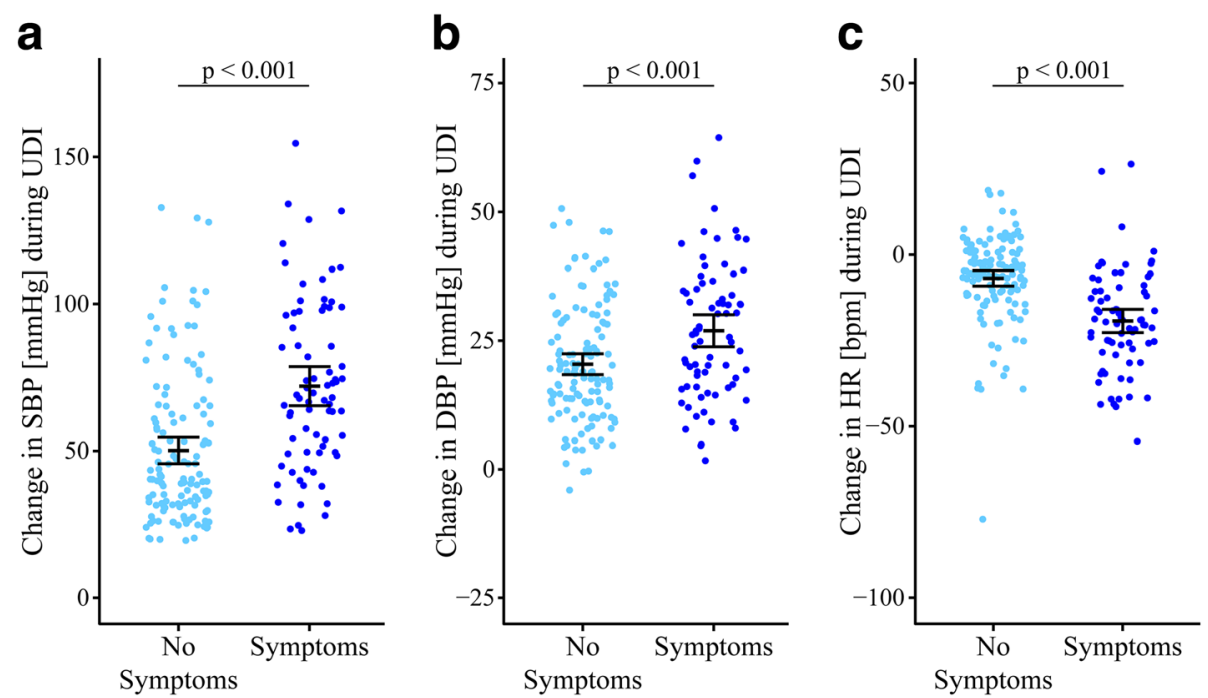

Fig. 4 Cardiovascular parameters during urodynamic investigation by symptomatic vs. asymptomatic AD. Cardiovascular changes in (a) SBP, (b) $\mathrm{DBP}$, and (c) HR in SCl patients with AD who have either presented symptoms (right side in dark blue) or not (left side in Maya blue). At the start of UDI, cardiovascular parameters were not significantly different between both groups. In patients with symptomatic AD, cardiovascular changes in SBP $(72,95 \% \mathrm{Cl} 67.6-76.7$ vs. 50, 95\% Cl 45.8-54.8 mmHg), DBP (27, 95\% Cl 25.0-29.1 vs. 21, 95\% Cl 18.5-22.6 mmHg) and HR (-19, 95\% Cl -21.6 to -16.7 vs. $-7,95 \% \mathrm{Cl}-9.0$ to -4.3$)$ during UDI were significantly different $(\mathrm{p}<0.001)$ compared to those of remaining patients. Each circle represents one patient's cardiovascular changes during UDI. Error bars represent mean and the $95 \% \mathrm{Cl}$ of cardiovascular changes; i.e., the worse out of two same session UDIs were used. AD autonomic dysreflexia, BPM beats per minute, $C l$ confidence interval, DBP diastolic blood pressure, $H R$ heart rate, SBP systolic blood pressure, SCI spinal cord injury, UDI urodynamic investigation 
cardiovascular function than neurological completeness of injury. However, we do not have enough data from all of our patients to investigate the effect of autonomic completeness on the incidence of $\mathrm{AD}$ and cardiovascular changes during UDI.

In line with Liu et al. [15], we found significantly different cardiovascular changes in patients with NDO compared to those without. Being considered a major cause to trigger $\mathrm{AD}$ [15] and leading to significant increases in arterial pressure [39], NDO seems to pose a significant health risk to patients with SCI. This is clinically relevant, as most patients with SCI suffer from NDO [40]. As a result of NDO, repeatedly increased intravesical pressures can lead to morphological changes of the urinary tract and increased risk of upper urinary tract complications in the long term $[4,41]$. The latter comprise vesico-uretero-renal reflux, hydronephrosis, impairment of renal functions, or at worst renal failure [4]. Treatment of NDO, i.e., with antimuscarinic drugs and intradetrusor onabotulinumtoxinA injections, results in reduction of intravesical pressure, improves quality of life, and has been successfully implemented into clinical practice and guidelines [3]. Given the potential of NDO to elicit AD, successful treatment of NDO could also have a positive effect on $\mathrm{AD}$ incidence and extent of related cardiovascular changes. In line with this hypothesis, Fougere et al. [42] provided evidence of effectively reducing the frequency and severity of $\mathrm{AD}$ after intradetrusor onabotulinumtoxinA injections in patients with SCI. By improving LUT function and concurrently reducing cardiovascular responses to LUT stimuli, treatment of NDO appears to have the capacity to lower the risk for AD-related long-term complications.

Although to the best of our knowledge this is the largest prospective cohort study investigating $A D$ using continuous cardiovascular changes in patients with suprasacral SCI suffering from NLUTD, some limitations should be addressed. Common conditions such as urinary tract infections, medications, and fluctuations of the neurological state can influence lower urinary tract function and consequently UDI and CVM parameters. Furthermore, as we only included those patients with SCI who are affected by NLUTD, which represents most SCI patients, it is difficult to say whether our results could also be extrapolated to SCI patients without NLUTD. Moreover, demonstrating the impact of SCI lesion level, completeness, and symptomatology of $\mathrm{AD}$ on cardiovascular changes during UDI, it would be of great interest to continuously monitor cardiovascular parameters during long-term ambulatory UDI to further assess the cardiovascular risk profile in patients with SCI.

Despite these limitations, our study is the first to provide evidence that $A D$ during UDI is predictable by lesion level and presence of NDO. Our results clearly underline the importance of continuous CVM during UDI in all patients with suprasacral SCI and emphasize the relevance of proactive NDO treatment. In this way, $\mathrm{AD}$ can be detected earlier and more frequently, which subsequently could lead to fewer episodes of AD-related complications during diagnostic assessment or at best none. To further protect patients with SCI, continuous CVM should also be considered as standard surveillance during other diagnostic interventions such as cystoscopy [9] and sperm retrieval [43].

\section{Conclusions}

Considering all potential health risks associated with $\mathrm{AD}$, such as seizures, stroke, retinal bleeding, or even death, we highly recommend continuous CVM during UDI in all patients with suprasacral SCI, since focusing on lesions at T6 or above would result in missing a relevant percentage of patients with AD. However, particular emphasis should be given to individuals with cervical lesions, as they are at highest risk for AD during UDI.

Given our previous experiences [16, 21], we propose performing same session repeat UDI with continuous CVM, which allows one to provide the treating urologist with more precise information on the extent of NLUTD and cardiovascular changes during UDI.

Moreover, we advise considering appropriate treatment of NDO, not only to protect the upper urinary tract from potential long-term damage, but also to improve quality of life and decrease the risk of AD. Following our recommendations will also allow for revealing findings of cardiovascular risk factors in patients with silent $\mathrm{AD}$ and might subsequently reduce the risk of potentially life-threating complications related to sudden hypertension during $\mathrm{AD}$.

\section{Additional file}

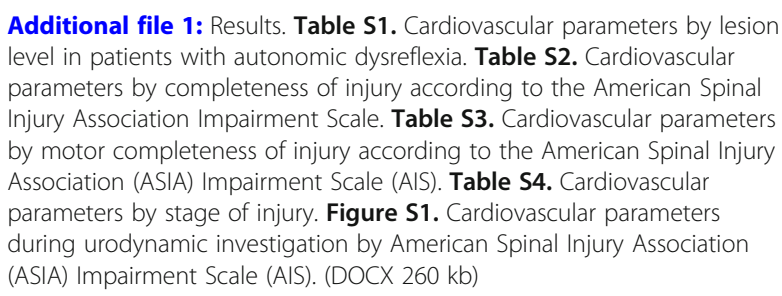

Additional file 1: Results. Table S1. Cardiovascular parameters by lesion level in patients with autonomic dysreflexia. Table S2. Cardiovascular parameters by completeness of injury according to the American Spinal Injury Association Impairment Scale. Table S3. Cardiovascular parameters by motor completeness of injury according to the American Spinal Injury Association (ASIA) Impairment Scale (AIS). Table S4. Cardiovascular parameters by stage of injury. Figure S1. Cardiovascular parameters during urodynamic investigation by American Spinal Injury Association (ASIA) Impairment Scale (AIS). (DOCX $260 \mathrm{~kb}$ )

\footnotetext{
Abbreviations

AD: Autonomic dysreflexia; AIS: American Spinal Injury Association Impairment Scale; ANOVA: Analysis of variance; AOR: Adjusted odds ratio; Cl: Confidence interval; CVS: Cardiovascular system; DBP: Diastolic blood pressure; EMSCl: European Multicenter Study about Spinal Cord Injury; HR: Heart rate; ICS: International Continence Society; ISAFSCI: International Standards to document remaining Autonomic Function after Spinal Cord Injury; ISNCSCl: International Standards for Neurological Classification of Spinal Cord Injury; LUT: Lower urinary tract; NDO: Neurogenic detrusor overactivity; NLUTD: Neurogenic lower urinary tract dysfunction; OR: Odds
} 
ratio; SBP: Systolic blood pressure; SCI: Spinal cord injury; SD: Standard deviation; SPN: Sympathetic pre-ganglionic neuron; UDI: Urodynamic investigation

\section{Acknowledgements}

We thank the patients for their participation. We thank Catherine R. Jutzeler (International Collaboration On Repair Discoveries (ICORD), University of British Columbia (UBC), Vancouver, Canada) for her assistance with the graphical design.

\section{Funding}

This work was funded by the Swiss National Science Foundation and the Swiss Continence Foundation. Matthias Walter is a 2017 Michael Smith Foundation for Health Research "Research Trainee Award" recipient, in partnership with the Rick Hansen Foundation. The sponsors of the study had no role in study design, data collection, data analysis, data interpretation, or writing of the report. All authors had full access to all the data in the study and responsibility for the decision to submit for publication.

\section{Availability of data and materials}

The datasets used and/or analyzed during the current study are available from the corresponding author on request.

\section{Authors' contributions}

According to the guidelines of the International Committee of Medical Journal Editors (ICMJE), all authors contributed to the four criteria. MW, SCK JJC, LL, MPS, UM, MS, AC, AVK, and TMK conceived and designed the study. MW, SCK, LL, MPS, UM, and TMK acquired the data. MW, SCK, JJC, LL, MPS, UM, MS, AC, AVK, and TMK analyzed and interpreted the data. MW, SCK, and TMK drafted the manuscript. JJC, LL, MPS, UM, MS, AC, AVK, and TMK critically revised the manuscript for important intellectual content. MW, SCK, $J \mathrm{JC}$, and TMK performed the statistical analysis. All authors read and approved the final manuscript.

\section{Ethics approval and consent to participate}

The local ethics committee (Kantonale Ethikkommission Zürich) approved this study (KEK-2010-0207). All patients gave written informed consent according to the Helsinki II declaration.

\section{Competing interests}

The authors declare that they have no competing interests.

\section{Publisher's Note}

Springer Nature remains neutral with regard to jurisdictional claims in published maps and institutional affiliations.

\section{Author details}

${ }^{1}$ Neuro-Urology, Spinal Cord Injury Center \& Research, University of Zürich, Balgrist University Hospital, Zürich, Switzerland. ${ }^{2}$ Neurology, Spinal Cord Injury Center \& Research, University of Zürich, Balgrist University Hospital, Zürich, Switzerland. ${ }^{3}$ International Collaboration On Repair Discoveries (ICORD), Faculty of Medicine, University of British Columbia, Vancouver, Canada.

\section{Received: 28 October 2017 Accepted: 20 March 2018}

\section{Published online: 13 April 2018}

\section{References}

1. Pavese C, Schneider MP, Schubert M, Curt A, Scivoletto G, Finazzi-Agro E, Mehnert U, Maier D, Abel R, Rohrich F, et al. Prediction of bladder outcomes after traumatic spinal cord injury: a longitudinal cohort study. PLoS Med. 2016;13(6):e1002041.

2. International perspectives on spinal cord injury. http://apps.who.int/iris/ bitstream/10665/94190/1/9789241564663_eng.pdf. Accessed 07 Mar 2018.

3. Groen J, Pannek J, Castro Diaz D, Del Popolo G, Gross T, Hamid R, Karsenty G, Kessler TM, Schneider M, t Hoen L, et al. Summary of European Association of Urology (EAU) Guidelines on Neuro-Urology. Eur Urol. 2016; 69(2):324-33.

4. Panicker JN, Fowler CJ, Kessler TM. Lower urinary tract dysfunction in the neurological patient: clinical assessment and management. Lancet Neurol. 2015;14(7):720-32.
5. Furlan JC, Fehlings MG. Cardiovascular complications after acute spinal cord injury: pathophysiology, diagnosis, and management. Neurosurg Focus. 2008;25(5):E13.

6. Karlsson AK. Autonomic dysreflexia. Spinal Cord. 1999;37(6):383-91.

7. Krassioukov AV, Karlsson AK, Wecht JM, Wuermser LA, Mathias CJ, Marino RJ. Assessment of autonomic dysfunction following spinal cord injury: rationale for additions to International Standards for Neurological Assessment. J Rehabil Res Dev. 2007:44(1):103-12.

8. Hubli M, Gee CM, Krassioukov AV. Refined assessment of blood pressure instability after spinal cord injury. Am J Hypertens. 2015; 28(2): 173-81.

9. Liu N, Fougere R, Zhou MW, Nigro MK, Krassioukov AV. Autonomic dysreflexia severity during urodynamics and cystoscopy in individuals with spinal cord injury. Spinal Cord. 2013;51(11):863-7.

10. Wan D, Krassioukov AV. Life-threatening outcomes associated with autonomic dysreflexia: a clinical review. J Spinal Cord Med. 2014;37(1):2-10.

11. Ho CP, Krassioukov AV. Autonomic dysreflexia and myocardial ischemia. Spinal Cord. 2010;48(9):714-5.

12. Pan SL, Wang YH, Lin HL, Chang CW, Wu TY, Hsieh ET. Intracerebral hemorrhage secondary to autonomic dysreflexia in a young person with incomplete C8 tetraplegia: a case report. Arch Phys Med Rehabil. 2005;86(3): 591-3.

13. Yarkony GM, Katz RT, Wu YC. Seizures secondary to autonomic dysreflexia. Arch Phys Med Rehabil. 1986;67(11):834-5.

14. Dolinak $D$, Balraj E. Autonomic dysreflexia and sudden death in people with traumatic spinal cord injury. Am J Forensic Med Pathol. 2007;28(2):95-8.

15. Liu N, Zhou M, Biering-Sorensen F, Krassioukov AV. latrogenic urological triggers of autonomic dysreflexia: a systematic review. Spinal Cord. 2015; 53(7):500-9.

16. Walter M, Knupfer SC, Leitner L, Mehnert U, Schubert M, Curt A, Kessler TM. Autonomic dysreflexia and repeatability of cardiovascular changes during same session repeat urodynamic investigation in women with spinal cord injury. World J Urol. 2016;34(3):391-7.

17. Kirshblum S, Waring W 3rd. Updates for the International Standards for Neurological Classification of Spinal Cord Injury. Phys Med Rehabil Clin N Am. 2014;25(3):505-17. vii

18. Abrams $P$, Cardozo L, Fall M, Griffiths $D$, Rosier $P$, Ulmsten U, van Kerrebroeck P, Victor A, Wein A. The standardisation of terminology of lower urinary tract function: report from the Standardisation Sub-committee of the International Continence Society. Neurourol Urodyn. 2002;21(2):167-78.

19. Schafer W, Abrams P, Liao L, Mattiasson A, Pesce F, Spangberg A, Sterling AM, Zinner NR, van Kerrebroeck P. Good urodynamic practices: uroflowmetry, filling cystometry, and pressure-flow studies. Neurourol Urodyn. 2002;21(3):261-74.

20. Inskip JA, Lucci VM, McGrath MS, Willms R, Claydon VE: A community perspective on bowel management and quality of life after spinal cord injury: the influence of autonomic dysreflexia. J Neurotrauma 2018. http:// dx.doi.org/10.1089/neu.2017.5343

21. Bellucci $\mathrm{CH}$, Wollner J, Gregorini F, Birnbock D, Kozomara M, Mehnert $U$, Kessler TM. Neurogenic lower urinary tract dysfunction—do we need same session repeat urodynamic investigations? J Urol. 2012;187(4):1318-23.

22. Schutte $A E$, Huisman HW, van Rooyen JM, Malan NT, Schutte R. Validation of the Finometer device for measurement of blood pressure in black women. J Hum Hypertens. 2004;18(2):79-84.

23. Krassioukov A, Biering-Sorensen F, Donovan W, Kennelly M, Kirshblum S, Krogh K, Alexander MS, Vogel L, Wecht J. International standards to document remaining autonomic function after spinal cord injury. I Spinal Cord Med. 2012;35(4):201-10.

24. Furusawa K, Tokuhiro A, Sugiyama H, lkeda A, Tajima F, Genda E, Uchida R, Tominaga T, Tanaka H, Magara A, et al. Incidence of symptomatic autonomic dysreflexia varies according to the bowel and bladder management techniques in patients with spinal cord injury. Spinal Cord. 2011;49(1):49-54.

25. Karlsson AK. Autonomic dysfunction in spinal cord injury: clinical presentation of symptoms and signs. Prog Brain Res. 2006;152:1-8.

26. Krassioukov A, Tomasone JR, Pak M, Craven BC, Ghotbi MH, Ethans K, Martin Ginis KA, Ford M, Krassioukov-Enns D. "The ABCs of AD": A prospective evaluation of the efficacy of an educational intervention to increase knowledge of autonomic dysreflexia management among emergency health care professionals. J Spinal Cord Med. 2016;39(2):190-6. 
27. Giannantoni A, Di Stasi SM, Scivoletto G, Mollo A, Silecchia A, Fuoco U, Vespasiani G. Autonomic dysreflexia during urodynamics. Spinal Cord. 1998; 36(11):756-60.

28. Huang YH, Bih LI, Chen GD, Lin CC, Chen SL, Chen WW. Autonomic dysreflexia during urodynamic examinations in patients with suprasacral spinal cord injury. Arch Phys Med Rehabil. 2011;92(9):1450-4.

29. Huang YH, Bih LI, Liao JM, Chen SL, Chou LW, Lin PH. Blood pressure and age associated with silent autonomic dysreflexia during urodynamic examinations in patients with spinal cord injury. Spinal Cord. 2013:51(5):401-5.

30. Calaresu FR, Yardley CP. Medullary basal sympathetic tone. Annu Rev Physiol. 1988:50:511-24.

31. Blackmer J. Rehabilitation medicine: 1. Autonomic dysreflexia. CMAJ. 2003; 169(9):931-5.

32. Krassioukov A. Autonomic function following cervical spinal cord injury. Respir Physiol Neurobiol. 2009;169(2):157-64.

33. Linsenmeyer TA, Campagnolo DI, Chou IH. Silent autonomic dysreflexia during voiding in men with spinal cord injuries. J Urol. 1996;155(2):519-22.

34. FitzGerald MJT, Gruener G, Mtui E. Clinical neuroanatomy and neuroscience. 6th ed. London: Saunders Elsevier; 2012.

35. Schünke $M$, Schulte $E$, Schumacher $U$, Ross LM. Atlas of anatomy: neck and internal organs. 1st ed. New York: Thieme; 2010.

36. Teasell RW, Arnold JM, Krassioukov A, Delaney GA. Cardiovascular consequences of loss of supraspinal control of the sympathetic nervous system after spinal cord injury. Arch Phys Med Rehabil. 2000;81(4):506-16.

37. Liu N, Zhou MW, Biering-Sorensen F, Krassioukov AV. Cardiovascular response during urodynamics in individuals with spinal cord injury. Spinal Cord. 2017;55(3):279-84.

38. West CR, Bellantoni A, Krassioukov AV. Cardiovascular function in individuals with incomplete spinal cord injury: a systematic review. Top Spinal Cord Inj Rehabil. 2013;19(4):267-78.

39. Schurch B, Knapp PA, Rossier AB. Autonomic hyperreflexia revisited. Urol Int. 1997;58(3):148-52.

40. Schops TF, Schneider MP, Steffen F, Ineichen BV, Mehnert U, Kessler TM. Neurogenic lower urinary tract dysfunction (NLUTD) in patients with spinal cord injury: long-term urodynamic findings. BJU Int. 2015;115(Suppl 6):33-8.

41. Hackler RH. A 25-year prospective mortality study in the spinal cord injured patient: comparison with the long-term living paraplegic. J Urol. 1977; 117(4):486-8.

42. Fougere RJ, Currie KD, Nigro MK, Stothers L, Rapoport D, Krassioukov AV. Reduction in bladder-related autonomic dysreflexia after onabotulinumtoxinA treatment in spinal cord injury. J Neurotrauma. 2016; 33(18):1651-7.

43. Sheel AW, Krassioukov AV, Inglis JT, Elliott SL. Autonomic dysreflexia during sperm retrieval in spinal cord injury: influence of lesion level and sildenafil citrate. J Appl Physiol. 2005;99(1):53-8.

\section{Submit your next manuscript to BioMed Central and we will help you at every step:}

- We accept pre-submission inquiries

- Our selector tool helps you to find the most relevant journal

- We provide round the clock customer support

- Convenient online submission

- Thorough peer review

- Inclusion in PubMed and all major indexing services

- Maximum visibility for your research

Submit your manuscript at www.biomedcentral.com/submit 